\title{
Investigation of collagen architecture in diseases of temporomandibular joint
}

\author{
Shailja Chatterjee ${ }^{1+*}$ and Sachin Jindal ${ }^{2 \dagger}$ \\ *Correspondence: shailjachatterjee@gmail.com \\ tThese authors contributed equally to this work. \\ ${ }^{1}$ Reader, Department of Oral Pathology, MMCDSR, M. M. University (Haryana), India. \\ ${ }^{2}$ Postgraduate student, Department of Oral Pathology, MMCDSR, M. M. University (Haryana), India.
}

\begin{abstract}
Background: Temporomandibular joint (TMJ) is a stress bearing structure. Its resilience and functions are supported by collagen architecture. Visualization of this collagen networking can be done under polarizing microscope. This network gets modified in a variety of conditions affecting the TMJ like- ankylosis, degenerative joint disorder, neoplastic conditions, trauma and ageing. The objective of this study is to analyze the histomorphological changes in TMJ conditions and correlate them with collagen architecture so as to project scoring criteria for distinguishing between osseous changes.

Methods: Paraffin based H and E sections of TMJ conditions were obtained and observed under polarizing microscopy. Sample distribution was as follows: Degenerative joint disease $(n=10)$, ankylosis $(n=5)$ and osteochondroma $(n=5)$. A scoring criterion was devised and cutoff value was determined.

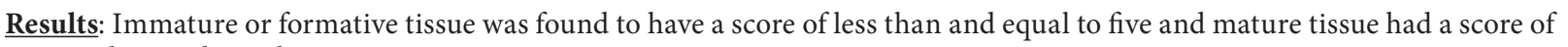
greater than and equal to six.

Conclusion: Scoring criterion proposed in this study is a reliable technique and can be used for confirming the histological architectural changes within a diseased TMJ.
\end{abstract}

Keywords: Temporomandibular joint, collagen, polarizing microscope, diarthrodial joint, articular cartilage

\section{Introduction}

Collagen fibrillar networking is the basic structure supporting the three-dimensional architecture of tissues. This provides tensile strength and volume maintenance [1]. Condylar pathologies may be developmental, traumatic, vascular, abnormal muscle pulling, nutritional, endocrinal, teratogenic and infectious in origin [2]. These disorders cause a change in structural integrity of TMJ histology and underlying collagen network. Most common etiology of TMJ ankylosis is after trauma or infection [3]. Few cases are congenital in origin [4,5]. Approximately $3 \%$ to $4 \%$ of population seek treatment for TMJ disorders, and roughly $70 \%$ of these patients suffer from disc displacement [6]. In this study, an attempt towards understanding architectural changes in collagen networking in various temporomandibular joint disorders has been made by means of polarizing microscopy.

\section{Materials and methods}

Hematoxylin and eosin stained paraffin-based sections were obtained from various temporomandibular joint conditions. Sample was distributed as follows: Degenerative joint disease $(n=10)$, ankylosis $(n=5)$ and osteochondroma $(n=5)$. Polarizing light microscopy was used to delineate collagen fibril architecture in tissue sections. A qualitative PLM (Polarizing light microscopy) scoring system was designed (Table 1). Institutional ethical committee clearance was obtained according to guidelines provided by Declaration of Helsinki. Radiographs were evaluated for all cases included in the study (Figure 9).

\section{Results and observation}

Diseased condylar tissue when observed under polarizing microscope exhibited a variety of patterns (Table 2). Woven bone showed an irregular fishnet-like pattern suggestive of a forming tissue. Mature bone had parallel lamellations corresponding to collagen mineralizing at regular intervals. This was observed as thick parallel lines. Cartilage had no birefringence.

Overall scores observed were:

a. Ankylosed condylar tissue (Figures 1 and 2):

3 (mature bone) +2 (thick) +1 (orange) +2 (parallel $)=8$.

b. Osteochondroma (Figures 5 and 6 ):

2 (parallel lamellations) +1 (orange) +2 (thick) +2 (parallel $)=7$.

c. Degenerative joint disease (Figures 3 and 4 ):

2 (parallel lamellations) +0 (light orange) +1 (thin) +2 (immature bone) $=5$.

2 (parallel lamellations) +2 (orange-green) +2 (thick) +3 (mature) $=9$. 
Chatterjee et al. Pathology Discovery 2013,

Table 1. Proposed PLM qualitative scoring system.

\begin{tabular}{lc}
\hline Microscopic feature & Score \\
\hline I. Pattern of collagen bundles: & 0 \\
\hline a. No birefringence: & 1 \\
b. Irregular pattern (woven bone): & 2 \\
c. Parallel lamellation pattern (mature bone): & \\
\hline II. Birefringence color: & 0 \\
\hline a. Light orange (immature): & 1 \\
b. Orange (mature): & 2 \\
c. Orange-green (maturing): & 1 \\
\hline III. Fibril thickness: & 2 \\
\hline a. Thin: & 1 \\
b. Thick: & 2 \\
\hline IV. Tissue type: & 3 \\
\hline a. Osteoid: & 4 \\
b. Woven bone: & \\
c. Mature lamellar bone: & \\
d. Cartilage: & \\
\hline
\end{tabular}

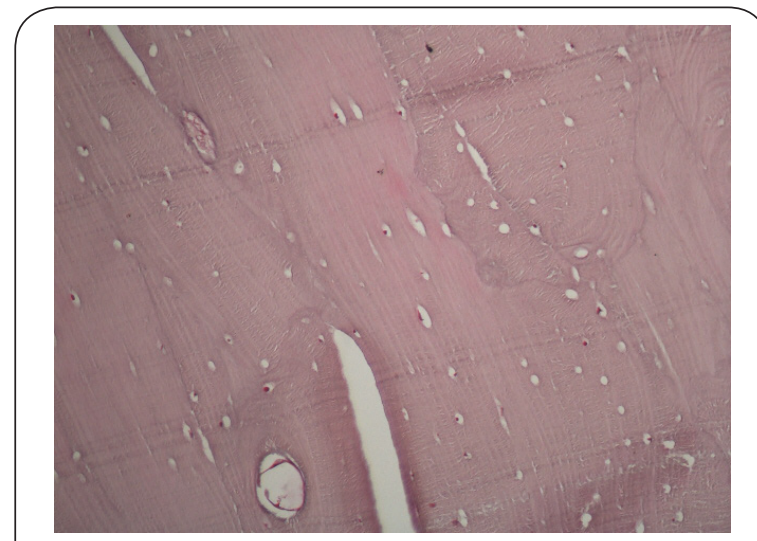

Figure 1. Photomicrograph showing mature bone with Osteocytes in ankylotic mass. (10X, H \& E).

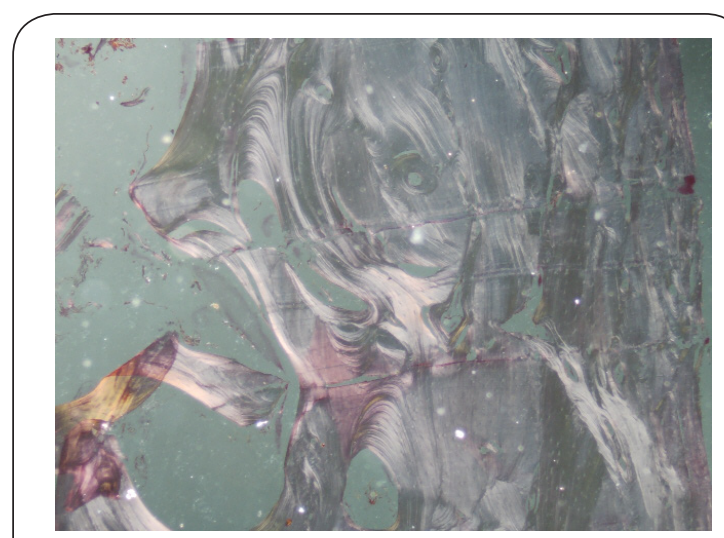

Figure 2. Photomicrograph depicting parallel orange collagen lamellations in ankylotic mass (10X, polarizing).

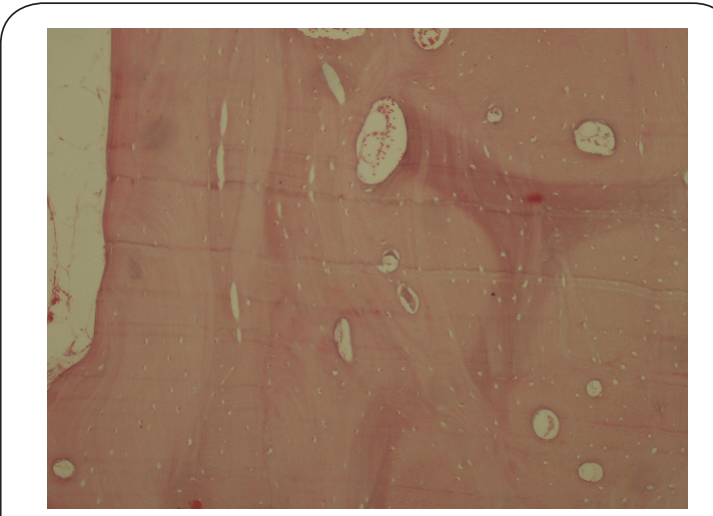

Figure 3. Photomicrographs depicting mature lamellar bone with absence of Osteocytes in degenerative joint disease (10X, $\mathrm{H} \& \mathrm{E}$ ).

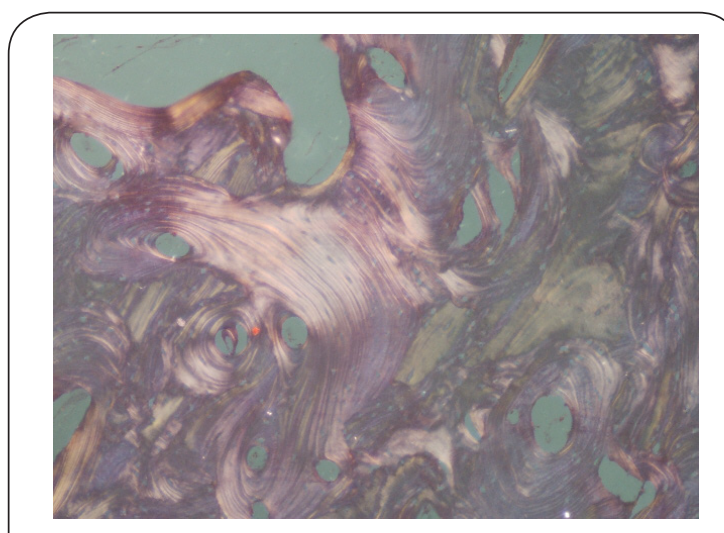

Figure 4. Haversian systems with concentric and parallel orange-green to light orange lamellations seen in degenerative joint disease (20 X, polarizing).

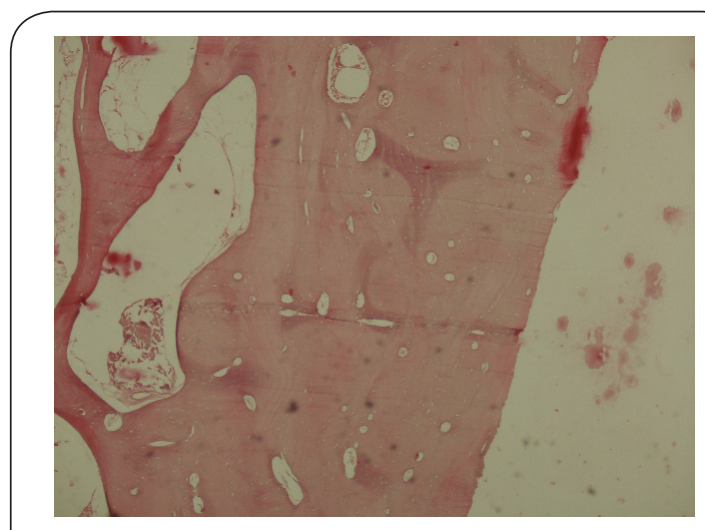

Figure 5. Mature bone with vital Osteocytes and bone marrow seen in osteochondroma (4X, H \& E).

\section{d. Forming condyle (Figures 7 and 8):}

1 (Irregular lamellations) +1 (orange) +1 (very thin) +1 (woven) $=4$. It was surmised from scores obtained that a score $\leq 5$ was indicative of a condylar tissue constituted by immature tissue 
Chatterjee et al. Pathology Discovery 2013,

http://www.hoajonline.com/journals/pdf/2052-7896-1-7.pdf

Table 2. Polarizing microscopy patterns and histomorphology in condylar diseases.

\begin{tabular}{|c|c|c|c|c|}
\hline Tissue type & Pattern of collagen bundles & Color of birefringence & Fibril diameter & Histomorphology \\
\hline Young condyle & Irregular (fishnet pattern) & Orange & Very thin & Woven bone \\
\hline Degenerative joint disease & Parallel lamellations & $\begin{array}{l}\text { Light orange } \\
\text { Orange-green }\end{array}$ & $\begin{array}{l}\text { Thin, Nonuniformly spaced } \\
\text { Thick, uniformly spaced }\end{array}$ & $\begin{array}{l}\text { Immature bone } \\
\text { Bone } \\
\text { Mature lamellar bone }\end{array}$ \\
\hline Ankylosis & Parallel lamellations & Orange & Thick, uniformly placed & Mature lamellar bone \\
\hline Osteochondroma & $\begin{array}{l}\text { Parallel lamellations } \\
\text { Parallel lamellations } \\
\text { No birefringence }\end{array}$ & $\begin{array}{l}\text { Orange } \\
\text { Orange }\end{array}$ & $\begin{array}{l}\text { Thick, uniformly spaced } \\
\text { Thin, Nonuniformly spaced } \\
\text {-- }\end{array}$ & $\begin{array}{l}\text { Mature lamellar bone } \\
\text { Osteoid } \\
\text { Cartilage }\end{array}$ \\
\hline
\end{tabular}

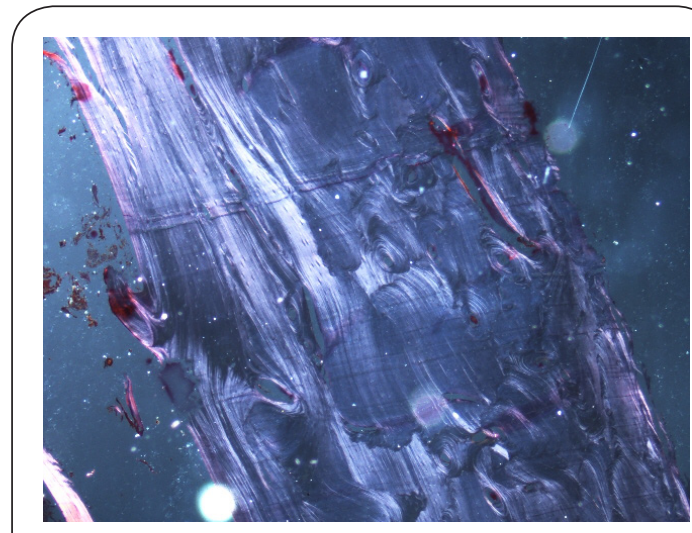

Figure 6. Photomicrograph showing thick orange parallel lamellations (20X, polarizing).

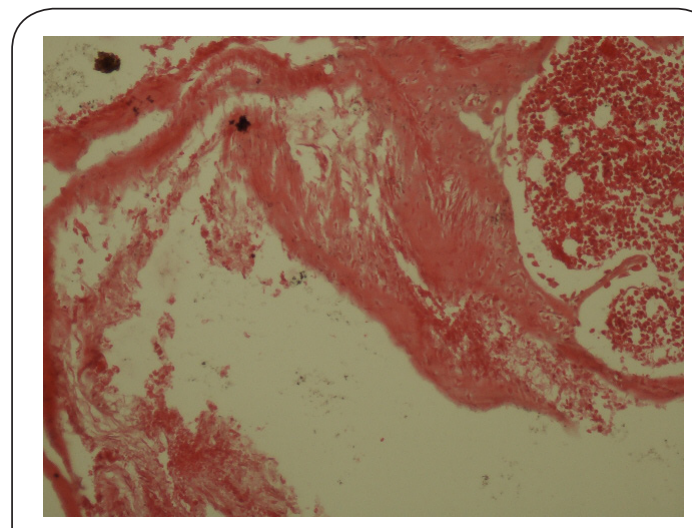

Figure 7. Photomicrograph showing woven bone with bone marrow tissue in forming condyle (20X, H \& E).

elements like osteoid, thin collagen fibrils and woven bone whereas a score of $\geq 6$ was indicative of a mature condylar tissue consisting of mature lamellar bone and thick, mature collagen fibers . Image analysis software (NIH Image J) was used for validating the color pixels and fiber thickness in each condition. For thick fibers, pixels varied in range of $183,162,157$ whereas, for thin fibers, pixels varied from $172,105,112$. For evaluation fiber thickness, each image was
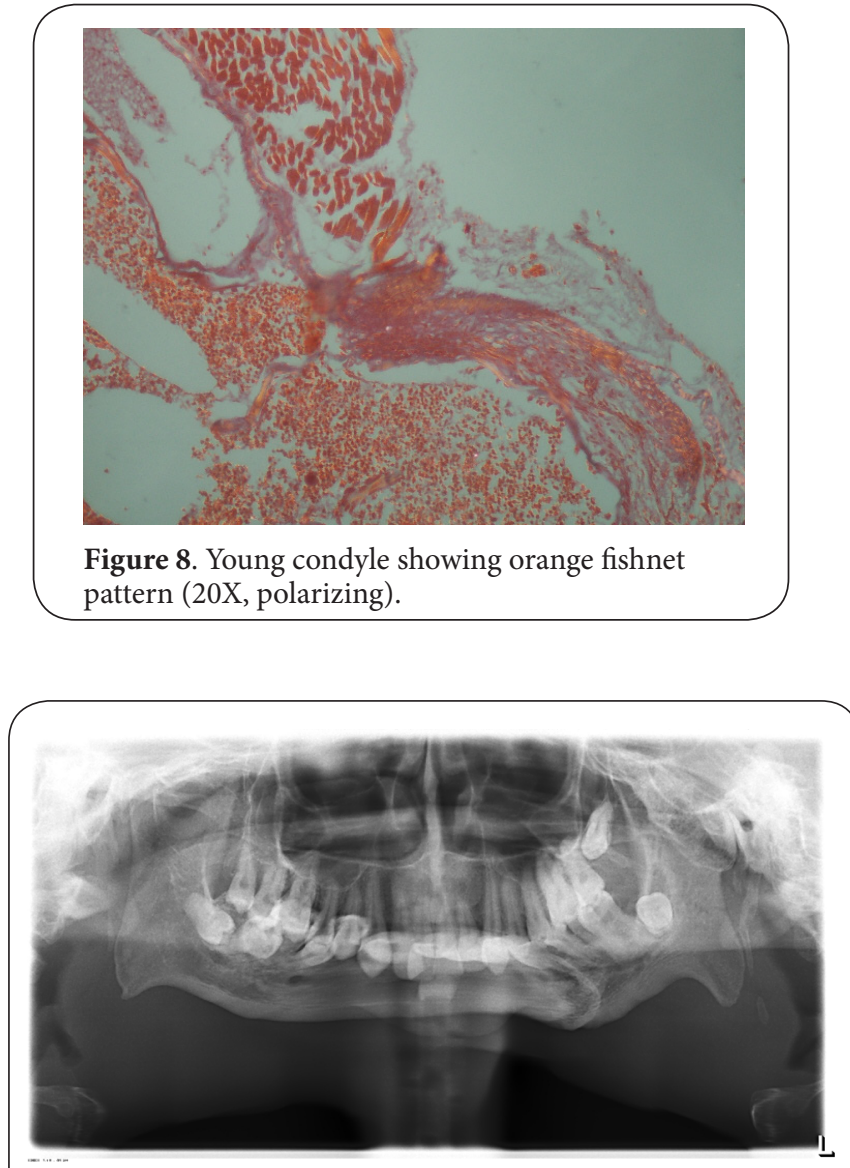

Figure 9. OPG depicting bilateral ankylotic mass.

contrasted using Image J software and thickness measured (Supplementary figures S1 and S2).

\section{Discussion}

The normal biomechanical behaviour of a diarthrodial joint is dependent on the composition and ultrastructural organization of the articular cartilage. The collagen network of articular cartilage protects the chondrocytes, resists tensile forces produced by compression as well as interstitial swelling, provides attachment for proteoglycans, and anchors the 
Chatterjee et al. Pathology Discovery 2013,

cartilage to the subchondral bone. Normally, articular cartilage that is regularly subjected to high levels of shear stress shows a high degree of collagen orientation and a thick superficial zone [1]. Collagen organization is critical factor responsible for load bearing and durability of TMJ. Many scoring systems have been proposed for studying the histomorphology and collagen orientation of the temporomandibular joint. These systems can be divided into a) semi-quantitative methods: OsScore and ICRS (International Cartilage Repair Society) I and II and b) qualitative technique like PLM (polarizing light microscopy) $[\mathbf{7}, \mathbf{8}]$. Polarized light microscopy is a traditional method for visualizing the collagen network architecture of condylar cartilage [9]. Polarized light microscopic technique can be used to measure collagen fibril orientation, parallelism, and birefringence $[\mathbf{1 0 , 1 2}]$. To overcome the drawbacks associated with polarizing microscopy as quoted by Rieppo et al., two observers viewed the slides and scoring was done with unanimous decision. Linear polarizing microscopy can be performed on a light microscope with addition of two filters, polarizer and analyzer. The polarizer is placed after the light source and ensures only linear polarized light i.e., light in a single plane that is perpendicular to direction of light propagation, is transmitted to the specimen. Optically anisotropic materials change the direction of light through birefringence. The fibrillar structure of collagen splits the incident polarized light into two orthogonal rays depending on the direction of collagen at each point in the section. The analyzer filter positioned after the specimen is at right angle to the polarizer. The polarized specimen is observed through an eyepiece. The objective of using polarizing light microscopy is to assess the extent to which a sample demonstrates collagen organization. This microscopic technique can be used to visualize fibrillar collagen for describe its network, changes in collagen orientation during ageing, validation of collagen imaging modalities and for observing changes during loading and degradation. Use of polarizing microscope for scoring purposes offers a systematic assessment of collagen organization. In this study, this technique for microscopic visualization has been used to demarcate a cutoff scoring value for immature and mature osseous structures in temporomandibular joint disorders. Less than five score value is suggestive of an ongoing formative process whereas a score of greater than or equal to six is indicator of a stabilized structure (no remodeling process). Here, a new scoring criteria using histomorphology as well as polarizing light microscope has been proposed. Almeida et al., performed histologic and histomorphologic analysis of collagen using picrosirius red. They compared the light intensity between diseased TMJ and normal controls using image analysis software. No statistical difference was observed between both groups. However, this was a qualitative analysis and did not study collagen birefringence in terms of collagen remodeling in immature and mature bone [10]. In a contradictory study studying effects of distraction osteogenesis on temporomandibular joint, disorganization of collagen fibers was observed (H \& E). However, no significant difference was found in histology and fiber thickness between the distracted and contralateral sides [11]. Panula et al., reported reduced birefringence and thinning of fibers in arthritic temporomandibular joints [1]. However, in this study, both thick and thin fibrils were found with varying intensities of birefringence. The authors have added few modifications in the PLM scoring proposed by Changoor et al., by including some additional groups so that the validity of the scoring system can be enhanced. No other study has included other pathologies affecting temporomandibular joint for studying collagen architecture using any of the methodologies available. Hence, further validation of the method proposed in this study is required and perhaps can be verified with a larger sample size as well as by other investigators.

\section{Conclusion}

TMJ is a synovial joint that is affected by numerous changes that can be age-related or pathologic in nature. The underlying collagen architecture provides mechanical support and resilience to the joint. The changes in collagen structure are reflected upon the structural changes and defects in the joint itself [12].

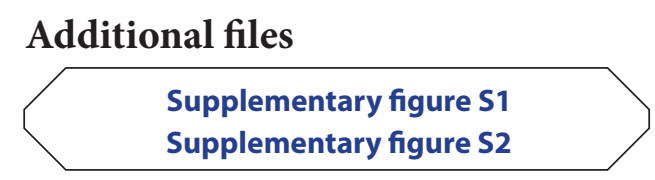

Competing interest

The authors declare that they have no competing interests.

Authors' contributions

\begin{tabular}{|l|c|c|}
\hline Authors' contributions & SC & SJ \\
\hline Research concept and design & $\checkmark$ & -- \\
\hline Collection and/or assembly of data & $\checkmark$ & $\checkmark$ \\
\hline Data analysis and interpretation & $\checkmark$ & $\checkmark$ \\
\hline Writing the article & $\checkmark$ & -- \\
\hline Critical revision of the article & $\checkmark$ & -- \\
\hline Final approval of article & $\checkmark$ & -- \\
\hline Statistical analysis & $\checkmark$ & -- \\
\hline
\end{tabular}

Acknowledgement

Author would like to acknowledge Department of Oral and Maxillofacial Surgery, MMCDSR, Mullana (India).

\section{Publication history}

EIC: Markus H. Frank, Harvard Medical School, USA. Received: 05-Sep-2013 Revised: 17-Sep-2013

Re-Revised: 01-Oct-2013 Accepted: 08-Oct-2013

Published: 18-Oct-2013

\section{References}

1. Panula HE, Hyttinen MM, Arokoski JP, Langsjo TK, Pelttari A, Kiviranta $\mathrm{I}$ and Helminen HJ. Articular cartilage superficial zone collagen 
Chatterjee et al. Pathology Discovery 2013,

http://www.hoajonline.com/journals/pdf/2052-7896-1-7.pdf

birefringence reduced and cartilage thickness increased before surface fibrillation in experimental osteoarthritis. Ann Rheum Dis. 1998; 57:23745. | Article | PubMed Abstract | PubMed Full Text

2. Rehman TA, Gibikote S, Ilango N, Thaj J, Sarawagi R and Gupta A. Bifid mandibular condyle with associated temporomandibular joint ankylosis: a computed tomography study of the patterns and morphological variations. Dentomaxillofac Radiol. 2009; 38:239-44. | Article | PubMed

3. Topazian RG. Etiology of Ankylosis of Temporomandibular Joint: Analysis of 44 Cases. J Oral Surg Anesth Hosp Dent Serv. 1964; 22:22733. | PubMed

4. Converse JM. Surgical release of bilateral, intractable, temporomandibular ankylosis. Plast Reconstr Surg. 1979; 64:404-7. I Article | PubMed

5. Tideman H and Doddridge M. TMJ ankylosis. Austr Dent J. 1987; 3:171177.

6. Isacsson G, Isberg A, Johansson AS and Larson O. Internal derangement of the temporomandibular joint: radiographic and histologic changes associated with severe pain. J Oral Maxillofac Surg. 1986; 44:771-8. I Article | PubMed

7. Changoor A, Tran-Khanh N, Methot S, Garon M, Hurtig MB, Shive MS and Buschmann MD. A polarized light microscopy method for accurate and reliable grading of collagen organization in cartilage repair. Osteoarthritis Cartilage. 2011; 19:126-35. | Article | PubMed

8. Roberts S, McCall IW, Darby AJ, Menage J, Evans H, Harrison PE and Richardson JB. Autologous chondrocyte implantation for cartilage repair: monitoring its success by magnetic resonance imaging and histology. Arthritis Res Ther. 2003; 5:R60-73. | Article | PubMed Abstract I PubMed Full Text

9. Mainil-Varlet $P$, Aigner $T$, Brittberg $M$, Bullough $P$, Hollander $A$, Hunziker E, Kandel R, Nehrer S, Pritzker K, Roberts S and Stauffer E. Histological assessment of cartilage repair: a report by the Histology Endpoint Committee of the International Cartilage Repair Society (ICRS). J Bone Joint Surg Am. 2003; 85-A Suppl 2:45-57. | Article | PubMed

10. Rieppo J, Hallikainen J, Jurvelin JS, Kiviranta I, Helminen $\mathrm{HJ}$ and Hyttinen MM. Practical considerations in the use of polarized light microscopy in the analysis of the collagen network in articular cartilage. Microsc Res Tech. 2008; 71:279-87. | Article | PubMed

11. Almeida LE, Baioni CS, Martins AP, Line SR, Noronha L, Trevilatto PC, de Lima AA, de Oliveira Filho MA and Ignacio SA. Histologic and histomorphometric analysis of posterior region of the human temporomandibular disc. Oral Surg Oral Med Oral Pathol Oral Radiol Endod. 2008; 105:e6-11. | Article | PubMed

12. Zou S, Hu J, Wang D, Li J and Tang Z. Changes in the temporomandibular joint after mandibular lengthening with different rates of distraction. Int J Adult Orthodon Orthognath Surg. 2001; 16:221-5. | Pdf | PubMed

Citation:

Chatterjee S and Jindal S. Investigation of collagen architecture in diseases of temporomandibular joint. Pathol Discov. 2013; 1:7.

http://dx.doi.org/10.7243/2052-7896-1-7 